\title{
Uncertainties in the simulation of groundwater recharge at different scales
}

\author{
H. Bogena ${ }^{2}$, R. Kunkel ${ }^{1}$, C. Montzka ${ }^{1}$, and F. Wendland ${ }^{1}$ \\ ${ }^{1}$ Research Centre Jülich, Systems Analysis and Technology Evaluation, 52425 Jülich, Germany \\ ${ }^{2}$ Research Centre Jülich, Agrosphere Institute: ICG IV, 52425 Jülich, Germany
}

Received: 7 January 2005 - Revised: 1 August 2005 - Accepted: 1 September 2005 - Published: 16 December 2005

\begin{abstract}
Digital spatial data always imply some kind of uncertainty. The source of this uncertainty can be found in their compilation as well as the conceptual design that causes a more or less exact abstraction of the real world, depending on the scale under consideration. Within the framework of hydrological modelling, in which numerous data sets from diverse sources of uneven quality are combined, the various uncertainties are accumulated.

In this study, the GROWA model is taken as an example to examine the effects of different types of uncertainties on the calculated groundwater recharge. Distributed input errors are determined for the parameters' slope and aspect using a Monte Carlo approach. Landcover classification uncertainties are analysed by using the conditional probabilities of a remote sensing classification procedure. The uncertainties of data ensembles at different scales and study areas are discussed.

The present uncertainty analysis showed that the Gaussian error propagation method is a useful technique for analysing the influence of input data on the simulated groundwater recharge. The uncertainties involved in the land use classification procedure and the digital elevation model can be significant in some parts of the study area. However, for the specific model used in this study it was shown that the precipitation uncertainties have the greatest impact on the total groundwater recharge error.
\end{abstract}

\section{Introduction}

The fact that digital spatial data always imply some kind of uncertainty has been an important topic in information science for over a decade (e.g. Goodchild and Gopal, 1989; Burrough and McDonnell, 1998). The source of this uncertainty is their compilation as well as the conceptual design that causes a more or less exact abstraction of the real world depending on the scale under consideration. These uncertainties are on the one hand of a spatial nature (geometrical uncertainty) and on the other hand of a numerical nature (thematic uncertainty) (Guptill and Morrison, 1995). Geometrical uncertainties are due to errors and impreciseness of the vector geometries of the digital cartography. Thematic uncertainties can be subdivided into qualitative and quantitative uncertainties. The former arise from the determination of a set of potential object types in a limited number of classes. An example of this is the probability classification method often used in remote sensing. Quantitative uncertainties refer to measurement or interpolation inaccuracies (e.g. precipitation).

Within the framework of hydrological modelling, in which numerous data sets of diverse sources, different thematic and uneven quality are combined, a superposition of the single uncertainties takes place (Moore, 1996). Therefore, a full integration of the data uncertainties into the model system is a prerequisite in order to achieve an assessment of the uncertainty of the model results due to input data uncertainties.

In this study, the Gaussian error propagation method (Bevington and Robinson, 1991) is used to determine the error of a calculated quantity by estimating the influence of the different uncertainty factors. In the present paper it is shown how the Gaussian error propagation method can be integrated in hydrological models in order to evaluate the influence of data uncertainties on the model results. In this study, the thematic uncertainties are quantified. The GROWA model (Kunkel and Wendland, 2002) is taken as an example and the effects of different types of uncertainties on the calculated water balance are discussed for different scaled data ensembles and study areas. 
Table 1. Databases for the groundwater recharge calculation at different scales.

\begin{tabular}{|c|c|c|c|}
\hline & Microscale & Mesoscale & Macroscale \\
\hline $\begin{array}{l}\text { Precipitation and } \\
\text { potential evapotranspira- } \\
\text { tion }\end{array}$ & $\begin{array}{l}\text { Interpolated grid } \\
(10 \mathrm{~m} \text { resolution }) \\
\text { German Weather Service }\end{array}$ & $\begin{array}{l}\text { Interpolated grid } \\
(25 \mathrm{~m} \text { resolution }) \\
\text { German Weather Service }\end{array}$ & $\begin{array}{l}\text { Interpolated grid } \\
(50 \mathrm{~m} \text { resolution }) \\
\text { German Weather Service }\end{array}$ \\
\hline Soil & $\begin{array}{l}\text { BK50 (1:50 000) } \\
\text { Geological Survey NRW }\end{array}$ & $\begin{array}{l}\text { BK50 (1:50000) } \\
\text { Geological Survey NRW }\end{array}$ & $\begin{array}{l}\text { BK50 (1:50 000) } \\
\text { Geological Survey NRW }\end{array}$ \\
\hline Hydrogeology & $\begin{array}{l}\text { HK25 (1:25 000) } \\
\text { Environmental State Agency NRW }\end{array}$ & $\begin{array}{l}\text { HK100 (1:100 000) } \\
\text { Geological Survey NRW }\end{array}$ & $\begin{array}{l}\text { HK100 (1:100 000) } \\
\text { Geological Survey NRW }\end{array}$ \\
\hline Landcover & $\begin{array}{l}\text { Landsat } 7 \text { ETM+ } \\
\text { (14.5 m resolution) } \\
\text { US Geological Survey }\end{array}$ & $\begin{array}{l}\text { Landsat } 7 \text { ETM+ } \\
\text { (14.5 m resolution) } \\
\text { US Geological Survey }\end{array}$ & $\begin{array}{l}\text { Landsat } 7 \text { ETM+ } \\
\text { ( } 28.5 \mathrm{~m} \text { resolution) } \\
\text { US Geological Survey }\end{array}$ \\
\hline Digital elevation model & $\begin{array}{l}\text { DGM5 (10 m resolution) } \\
\text { Land Surveying Office NRW }\end{array}$ & $\begin{array}{l}\text { DGM50 (25 m resolution) } \\
\text { Land Surveying Office NRW }\end{array}$ & $\begin{array}{l}\text { DGM50 (50 m resolution) } \\
\text { Land Surveying Office NRW }\end{array}$ \\
\hline
\end{tabular}

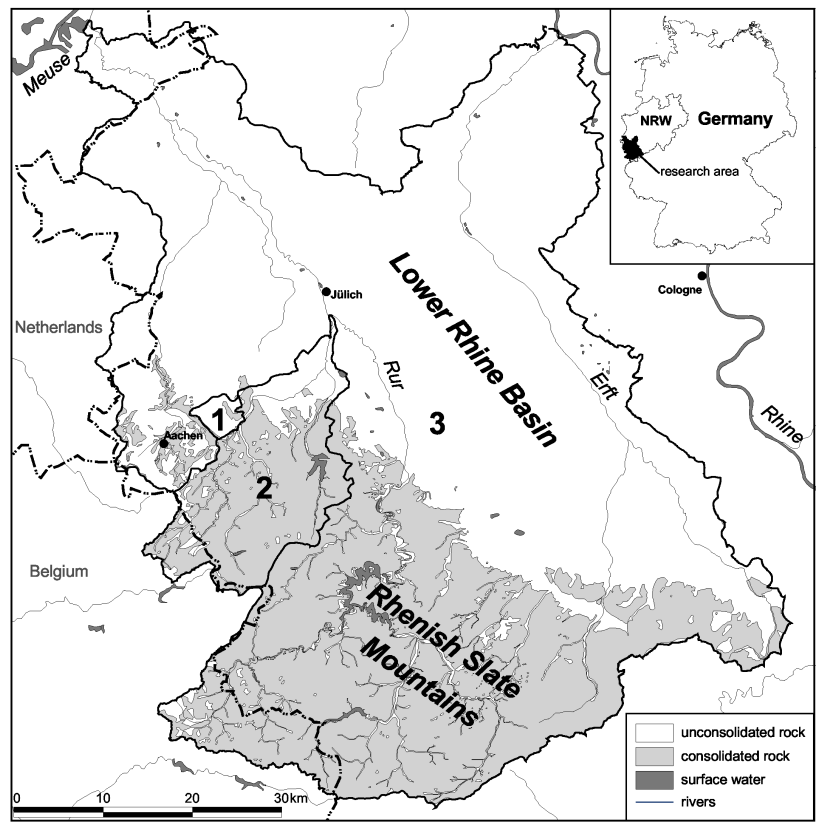

Fig. 1. The three test sites Saubach [1], Inde [2] and Rur and Erft [3] and the distribution of unconsolidated and consolidated rock regions in the research area.

\section{Study area}

The area under investigation is located in the west of Germany, in the south-western part of the Federal State of North Rhine-Westphalia (NRW) (Fig. 1). This area was selected in particular from the perspective that the greatest possible variability of natural resources should be represented, which are then also reflected in the data availability, resolution and quality.

The area under investigation comprises the catchment areas of the rivers Rur and Erft, which are direct tributaries of the Meuse (Rur) and the Rhine (Erft). The area is situated in the transition region between the Rhenish slate mountains and the northern outliers of the Lower Rhine Basin and extends beyond the national boundaries of Germany itself. More than half of the entire catchment area of the Rur River is covered by consolidated rock, whereas the catchment area of the Erft river only has solid rock on its southern boundaries.

The uncertainty evaluation is performed for three different scales (micro-, meso-, macroscale). Three study areas of different sizes were selected, where the smaller catchment areas are part of the bigger ones (see Fig. 1): the catchment areas of the River Rur and River Erft $\left(4125 \mathrm{~km}^{2}\right)$, catchment area of the River Inde $\left(353 \mathrm{~km}^{2}\right)$ and the catchment area of the small Saubach brook located northeast of Aachen $\left(16 \mathrm{~km}^{2}\right)$.

\section{Data}

The data sets used for this study are incorporated in a staggered resolution corresponding to the individual scale ranges (see Table 1). As far as possible, appropriate data sets of the considered scales were used. If no appropriate data set for the treated scale was available, the usability of data sets of a higher scale was investigated.

The uncertainties in the data sets have to be estimated since exact error specifications are hardly available. Therefore, special methodologies have to be applied in order to get a reliable estimation of the data uncertainties. The Monte Carlo methodology is an appropriate way to assess qualitative uncertainties of spatial data sets (Endreny and Wood, 2001). For example, an absolute accuracy value of $5 \mathrm{~m}$ is given for the digital elevation model DGM50 (Land Surveying Office NRW). Since the GROWA model needs slope and aspect as input parameters, it is important to know how the error of the digital elevation model propagates to the slope and aspect map. Therefore the error propagation is analysed 


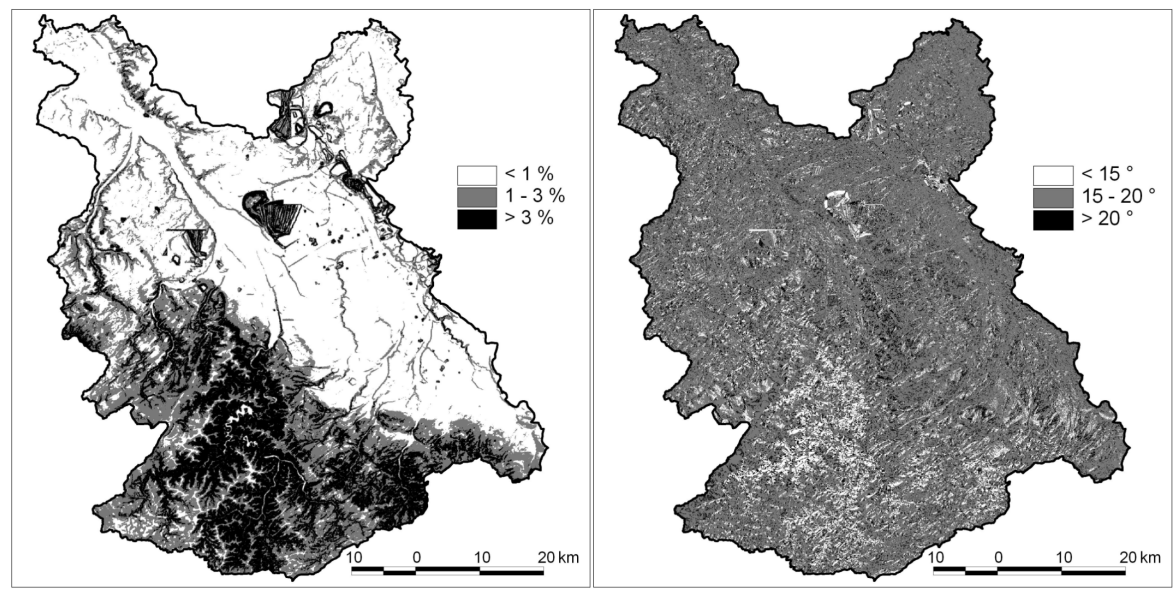

Fig. 2. The uncertainty of the hillslope map (left) and of the aspect map (right) for the macroscale study area.

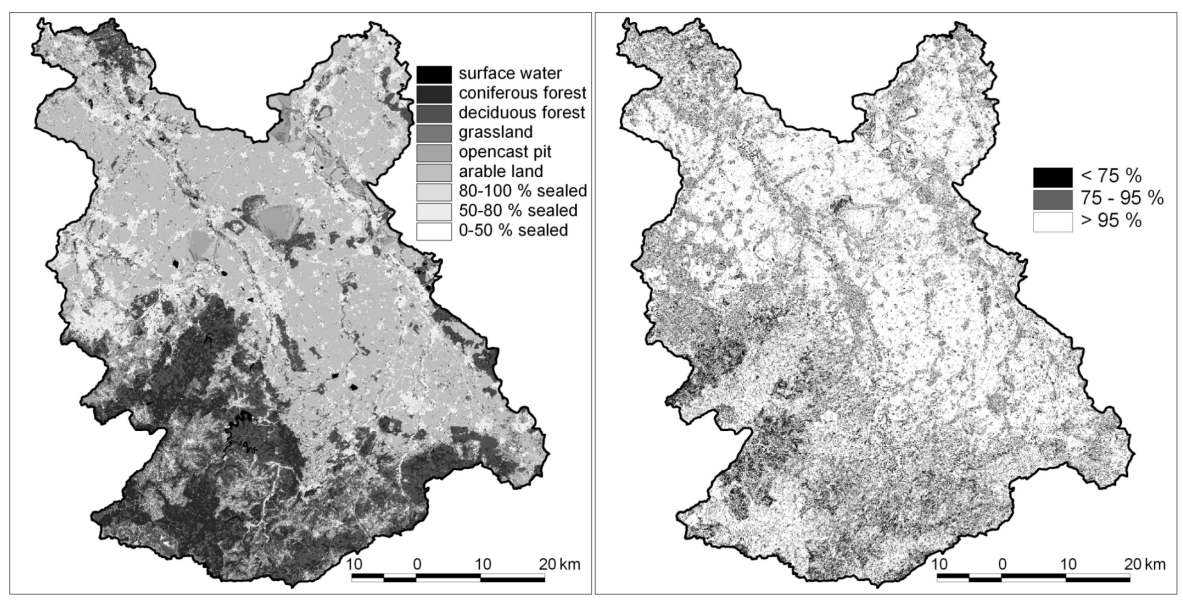

Fig. 3. Landcover classification of the macroscale study area (left) and the corresponding conditional probabilities of the supervised classification procedure.

by generating 200 stochastic realisations of the uncertain DEM. This is done by taking for each grid cell a random number drawn from an error probability distribution with a standard deviation of $5 \mathrm{~m}$. For each realisation a slope map is calculated, it is thus possible to calculate the standard deviation for all locations (Fig. 2, left). The aspect uncertainty is derived accordingly (Fig. 2, right).

In order to assess qualitative uncertainties a different approach has to be applied. For example, in this study the landcover is categorised from LANDSAT 7 data using a feed forward neural network procedure (Fig. 3, left). This method is used in remote sensing in order to group each pixel of a satellite image into categories representing different spectral classes which are subsequently related to landcover categories. One important advantage of the neural network procedure is that no information about the class-specific probability distribution is needed, i.e. the frequency of grey values in a class need not be normally distributed (Canty, 1999). In such a supervised classification procedure the conditional probabilities (Fig. 3, right) are given as a by-product and, thus, can be used as an error matrix (Heuvelink, 2002).
The landcover category with the highest classification probability is water (on average 98.8\%) whereas grassland shows the lowest classification probability (on average $86.3 \%$ ). In order to evaluate the propagation of the landcover classification uncertainty on the groundwater recharge calculation two different simulations are compared. In the first simulation the standard classification result is used and in the second conditional probabilities are used instead. Table 2 lists the averaged uncertainty values of landcover classifications and the slope and aspect maps used in this study.

The mean uncertainty values of the landcover map are calculated from the conditional probability distribution (Fig. 4). The mean uncertainty of the landcover classification ranges between $6.55 \%$ in the Rur and Erft catchment areas and $9.03 \%$ in the Inde catchment. The lower landcover classification probability in the Inde catchment is due to a high proportion of small-sized grassland parcels in this region.

The climatic data of the period 1979-1999 were provided by the German Meteorological Service (DWD). The basis for establishing the area-wide climate data is the climate and precipitation stations of the DWD. The station values were 
Table 2. Averaged uncertainties of the landcover, slope and aspect maps for the different study areas and data ensembles.

\begin{tabular}{lccccc}
\hline $\begin{array}{l}\text { Scale of the data set } \\
\text { Region }\end{array}$ & $\begin{array}{c}\text { Microscale } \\
\text { Saubach }\end{array}$ & \multicolumn{2}{c}{ Mesoscale } & \multicolumn{2}{c}{ Macroscale } \\
& Saubach & Inde & Saubach & Rur and Erft \\
\hline Landcover & $7.18 \%$ & $7.26 \%$ & $9.03 \%$ & $7.12 \%$ & $6.55 \%$ \\
Slope & $1.16 \%$ & $1.60 \%$ & $2.72 \%$ & $1.31 \%$ & $1.56 \%$ \\
Aspect & $17.98^{\circ}$ & $18.53^{\circ}$ & $18.2^{\circ}$ & $18.12^{\circ}$ & $17.96^{\circ}$ \\
\hline
\end{tabular}

regionalised using the IDW method (inverse distance weighting interpolation) including an elevation correction function (Müller-Westermeier et al., 1995). The potential evapotranspiration rates were determined according to Wendling (1995), in which the reference evapotranspiration (Allen et al., 1998) is modified for calculating long-term evapotranspiration rates (ATV-DVWK, 2002).

If uncertainty information is not available, general assumptions for the potential data error have to be made. In this study, the uncertainty information for the data sets is provided by the German Weather Service. In order to approximately indicate the spatial interpolation errors, a stationby-station cross validation was employed for the macroscale study area using the available DWD climate stations. A mean error of about $10 \%$ was found for 24 interpolation realisations using the IDW method. Therefore, a general error of $10 \%$ is assumed for the input parameters of precipitation and potential evaporation. The systematic errors of the measurements (e.g. wind-induced losses, wetting and evaporation losses) are not considered in this study. Since no uncertainty information was available from the Geological Survey NRW a general error of $10 \%$ is also assumed for the soil water content available to plants.

\section{The GROWA model}

The empirical GROWA model (Kunkel and Wendland, 2002) was chosen for estimating the groundwater recharge. The GROWA model consists of several modules for determining the long-term annual averages of water-balance components, namely actual evapotranspiration, total discharge, direct runoff and groundwater recharge, as described in detail in Kunkel and Wendland (2002). The calculation of total discharge is based on an empirical method developed by Renger and Wessolek (1996), which takes into account various forms of landcover (arable land, grassland, deciduous forest, coniferous forest) for flat rural areas at some distance from the groundwater table.

Several extensions were developed and implemented in the model scheme, allowing an area-wide application of the GROWA model. In the case of a site being affected by groundwater, actual evaporation is set to a maximal evaporation rate, which is calculated according to Glugla et al. (2002). Mean annual capillary rise is calculated in a vegetation-specific way considering the mean annual rate and the mean duration of capillary rise. In the case of high relief terrains, a relief correction function according to Golf (1981) is introduced that considers aspect and slope gradient. In the case of urban areas, a correction factor is introduced to account for the effect of sealing on the actual evaporation rate. The values of these factors are based on investigations by Wessolek and Facklam (1997). The following equation shows the generalised form for the calculation of total discharge $\left(Q_{\text {total }}\right)$ in the GROWA model:

$$
\begin{aligned}
& Q_{\text {total }}=P_{\text {year }}-f_{h}(v, \zeta) \cdot\left[a \cdot P_{s u}+b \cdot P_{w i}+c \cdot \log \left(W_{p l}\right)\right. \\
& \left.+d \cdot E T_{\text {pot }}+e+f_{d} \cdot D_{\text {seal }}\right]
\end{aligned}
$$

$P_{\text {year }}:$ Annual precipitation $[\mathrm{mm} / \mathrm{a}]$

$f_{h}(v, \zeta)$ : Relief correction function ( $\nu=$ slope, $\zeta=$ aspect) [-]

$a, b, c, d, e$ : Land-use-specific coefficients [-]

$P_{w i}, P_{s u}:$ Winter and summer precipitation $[\mathrm{mm} / \mathrm{a}]$

$W_{p l}$ : Soil water content available to plants [mm]

$E T_{\text {pot }}$ : Annual potential evapotranspiration [mm/a]

$f_{d}$ : Correction factor [-]

$D_{\text {seal }}$ : Sealing [\%]

The GROWA model separates groundwater runoff $\left(Q_{G W}\right)$ from total discharge using baseflow indices (BFI), which describe groundwater runoff as a constant fraction of the total runoff depending on specific area properties, e.g. slope gradient, soil and hydrogeological properties as well as the degree of surface sealing (Bogena et al., 2005).

$Q_{G W}=\mathrm{BFI} \cdot Q_{\mathrm{total}}$

In order to analyse the influence of data uncertainties on the model results the Gauß error propagation method is assessed by regarding the derivation of the model result with respect to the erroneous quantities multiplied by the total uncertainty of the quantities:

$$
\Delta^{2} Q_{g w}=\sum_{x}\left\{\left(\frac{\partial Q_{g w}}{\partial x} \Delta^{2} x\right)^{2}+\sum_{y(y \neq x)} \frac{\partial Q_{g w}}{\partial x} \cdot \frac{\partial Q_{g w}}{\partial y} \cdot \operatorname{Cov}(x, y)\right\}
$$

where $x$ and $y$ are abbreviations of the input parameters, e.g. either $P_{s u}, P_{w i}, W_{p l}, E T_{\mathrm{pot}}, D_{\text {seal }}, f_{h}$ or BFI and $\operatorname{Cov}(x, y)$ is the correlation of the input parameters.

The second term represents the influence of correlations between the individual input parameters. In this context 


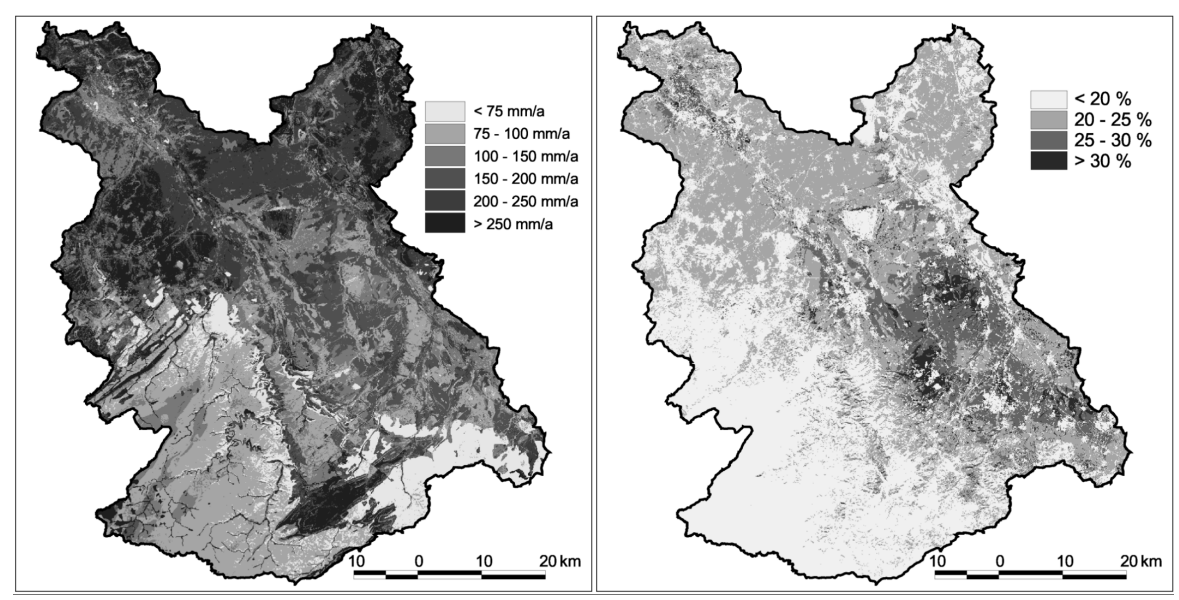

Fig. 4. Groundwater recharge in the macroscale study area (left) and the corresponding uncertainties (right).

the term "correlation" needs to be distinguished into spatial and statistical correlation. A spatial correlation between two quantities $\mathrm{A}$ and $\mathrm{B}$ is given, if large numbers of $\mathrm{A}$ are typically correlated to either large (positive correlation) or small (negative correlation) of B. This type of correlation can usually be found for precipitation and potential evapotranspiration fields. However, the statistical correlation means that an error in the measurement of determination of quantity A has a direct impact on the error of quantity B. If quantities are regarded, which are measured individually or calculated from different parameters, the statistical correlation of the errors can be neglected in most cases. Since the Gaussian error propagation is related to statistical errors exclusively, the input parameters for the calculation of groundwater recharge can be regarded as being independent. In this case, the statistical correlation $\operatorname{Cov}(x, y)$ in Eq. (3) is zero.

Differentiation of Eq. (1) and (2) according to Eq. (3) leads to the following equation:

$$
\begin{aligned}
& \Delta^{2} Q_{G W}=\mathrm{BFI}^{2} \cdot\left\{\left(1-f_{h} \cdot a\right)^{2} \cdot \Delta^{2} P_{s u}+\left(1-f_{h} \cdot b\right)^{2} \cdot \Delta^{2} P_{w i}\right. \\
& \left.+\left[f_{h} \cdot c \cdot \log (e) \cdot \frac{\Delta W_{p l}}{W_{p l}}\right]^{2}\right\}+\mathrm{BFI}^{2} \cdot\left\{f_{h}^{2} \cdot d^{2} \cdot \Delta^{2} E T_{\mathrm{pot}}+f_{h}^{2} \cdot f_{d}^{2} \cdot \Delta^{2} D_{\text {seal }}\right\} \\
& +\frac{1}{f_{h}^{2}} \cdot\left[\frac{Q_{g w}}{\mathrm{BFI}}-P_{j}\right]^{2}+Q_{g w}^{2} \cdot \frac{\Delta^{2} \mathrm{BFI}}{\mathrm{BFI}^{2}}
\end{aligned}
$$

\section{Results}

Figure 4 shows the results of the groundwater recharge calculation for the macroscale study area (left) and the corresponding uncertainties as a result of the uncertainties of all data sets used (right). In the consolidated rock region, the low hydraulic conductivity of the solid rocks leads to groundwater recharge rates that are often less than $100 \mathrm{~mm} / \mathrm{a}$. Only the karstified carbonate rocks show significantly higher hydraulic conductivities and the groundwater recharge rate

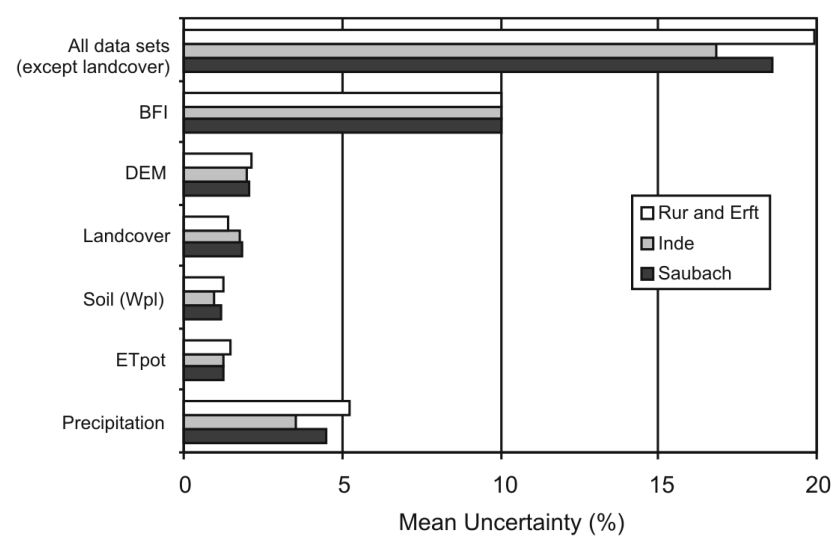

Fig. 5. The averaged uncertainties in percent of the mean groundwater recharge for the study areas as a result of the considered uncertainties of the data sets.

increases to more than $300 \mathrm{~mm} / \mathrm{a}$. In the unconsolidated rock region, groundwater recharge levels between 200 and $300 \mathrm{~mm} / \mathrm{a}$ are most common. This distinct dichotomy in the distribution of groundwater recharge rates is also apparent for the corresponding uncertainties. Most parts of the consolidated rock region show uncertainties well below 20\%, except for the karstified carbonate rocks with significantly higher values (more than 30\%). The unconsolidated rock region, on the other hand, shows uncertainties between 15 and $40 \%$.

In Fig. 5 the results of the uncertainty analysis for the study areas are shown. In order to facilitate an analysis of the differently scaled data ensembles on the calculated groundwater recharge, averaged values of the uncertainties in percent of the mean groundwater recharge are calculated. The differences between the scales cannot be generalised since the identified uncertainties are determined by the individual characteristics of the catchment area and the available database. For example, the mean groundwater recharge error that results from the uncertainties of the mesoscale data en- 
semble (Inde) is mostly lower. However, the averaged errors for the Saubach catchment are quite similar to the macroscale data ensemble.

The uncertainty in groundwater recharge due to the BFI values is equivalent to the assumed BFI error $10 \%$ because of the simple BFI approach (Eq. 2). The precipitation error has also an noteworthy impact on the uncertainty of the simulation result. By assuming a global precipitation error of $10 \%$ in most cases a mean groundwater recharge error from 3.6\% (Inde) to 5.3\% (Rur and Erft) are calculated. The other input data uncertainties considered only produce groundwater recharge errors below $3 \%$.

The differences between the data ensembles are very low. A higher resolution of the landcover classification map and the digital elevation model did not produce significantly lower groundwater recharge errors. However, it has to be considered that this study did not include the evaluation of the location accuracy. It can be assumed that higher resolutions of geographic data will lead to lower location uncertainties.

\section{Conclusions}

The Gaussian error propagation method is a usefully technique for analysing the influence of input data on the simulated groundwater recharge. The present uncertainty analysis showed that the BFI and precipitation uncertainties had the greatest impact on the total groundwater recharge error. This result is achieved by using a specific model and is therefore not simply transferable to other hydrological models. Furthermore, it has to be noted that this analysis has the character of a worst case study, since the climate parameter used in this study shows a significant correlation.

This study presents an approach for an uncertainty analysis that may be applicable for other models and which is also transferable to other regions. However, a prerequisite for an uncertainty evaluation is sound error specifications of the data sets. Methods like the Monte Carlo approach shown in this study are only a surrogate and can only give an approximation of the real errors. Therefore, in the future survey organisations should more frequently determine and record the qualities of each survey and add an extra attribute to the data set documenting, for instance, a conditional probability value. This information could be easily implemented in the uncertainty assessment methodology for groundwater recharge evaluation presented in this paper and would greatly improve the reliability of the uncertainty assessment.

Acknowledgements. Parts of this work are funded in the GEOTECHNOLOGIEN programme by the Federal Ministry for Education and Research (BMBF) and the German Research Foundation (DFG) with publication no. GEOTECH-111.

\section{References}

Allen, R. G., Pereiro, L. S., Raes, D., and Smith, M.: Crop evapotranspiration: Guidelines for computing crop requirements, Irrigation and Drainage paper 56, FAO, Rome, 1998.

ATV-DVWK: Verdunstung in Bezug zu Landnutzung, Bewuchs und Boden, Merkblatt ATV-DVWK M 504, 139 pp., Hennef, 2001.

Bevington, P. R. and Robinson, D.K.: Data Reduction and Error Analysis for The Physical Sciences, McGraw-Hill, 328 pp. 1991.

Bogena, H., Kunkel, R., Schöbel, T., Schrey, H. P., and Wendland, F.: Distributed modelling of groundwater recharge at the macroscale, Ecological Modelling, 187, 15-26, 2005.

Burrough, P. A. and McDonnell, R. A.: Principles of Geographical Information Systems, 2nd Edition, Oxford University Press, 333 pp., 1998.

Canty, M. J.: Fernerkundung mit neuronalen Netzen. Theorie Algorithmen - Programme, Expert Verlag, 208 pp., Renningen, 1999.

Endreny, T. A. and Wood, E. F.: Representing elevation uncertainty in runoff modelling and flowpath mapping, Hydrol. Processes, 15, 2223-2236, 2001

Glugla, G., Jankiewicz, P., Rachimow, C., Lojek, K., Richter, K., Fürtig, G., and Krahe, P.: Wasserhaushaltsverfahren BAGLUVA zur Berechnung vieljähriger Mittelwerte der tatsächlichen Verdunstung und des Gesamtabflusses, BfG-Bericht, 1342, Bundesanstalt für Gewässerkunde, Berlin, 2002.

Goodchild, M. F. and Gopal, S.: Accuracy of Spatial Databases, Taylor and Francis, Basingstoke, 290 pp., 1989.

Golf, W.: Ermittlung der Wasserressourcen im Mittelgebirge, Wasserwirtschaft-Wassertechnik, 31, 93-95, 1981.

Guptill, S. C. and Morrison, J.: The elements of spatial data quality, Elsevier, 202 pp., Amsterdam, 1995.

Heuvelink, G. B. M. : Analysing Uncertainty Propagation in GIS: Why is it not that Simple?, in: Uncertainty in Remote Sensing and GIS, edited by: Foody, G. M. and Atkinson, P. M., Wiley, Chichester, 155-165, 2002.

Kunkel, R. and Wendland, F.: The GROWA98 model for water balance analysis in large river basins, J. Hydrol., 259, 152-162, 2002.

Moore, I. D.: Hydrological modelling and GIS, in: GIS and Environmental Modeling: Progress and Research Issues, edited by: Goodchild, M. F., Steyaert T., Parks, B. O., Johnston, C., Maidment, D., Crane, M., and Glendinning, S., GIS World Books, Fort Collins, 143-148, 1996.

Müller-Westermeier, G.: Numerische Verfahren zur Erstellung klimatologischer Karten, Berichte des Deutschen Wetterdienstes, 193, 12 pp., Offenbach am Main, 1995.

Renger, M. and Wessolek, G.: Berechnung der Verdunstungsjahresnummern einzelner Jahre, in: DVWK-Merkblätter zur Wasserwirtschaft, 238, 47, Bonn, 1996.

Wendling, U.: Berechnung der Gras-Referenzverdunstung mit der FAO Penman-Monteith-Beziehung, Wasserwirtschaft, 85(12), 602-604, 1995.

Wessolek, G. and Facklam, M.: Standorteigenschaften und Wasserhaushalt von versiegelten Flächen, Z. Pflanzenernährung Bodenkunde, 160, 41-46, 1997. 